\title{
Stanford type a aortic dissection with cerebral infarction: a rare case report
}

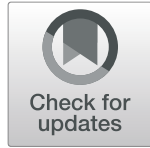

Jie Wang ${ }^{*}$, Li-Rong $\mathrm{Wu}^{\dagger}$ and Xin Xie

\begin{abstract}
Background: Aortic dissection $(A \circ D)$ is a disease with a high mortality rate. Its clinical manifestations are diverse and covert, which makes diagnosis and treatment challenging. Here, we report a very rare case of aortic dissection leading to bilateral cerebral cortex ischaemia and epilepsy.

Case presentation: A 54-year-old man was admitted to the hospital with acute onset of right limb weakness accompanied by slurred speech. He had a history of hypertension as well as tobacco and alcohol use. The patient was found to have aphasia and right hemiplegia on physical examination. No bleeding was seen on the skull CT. Acute cerebral infarction was considered after admission, and rt-PA was administered for intravenous thrombolysis. During intravenous thrombolysis, the patient suddenly developed epilepsy, and diazepam was given immediately by intravenous injection to control the symptoms. Emergency skull diffusion-weighted imaging (DWI) was performed, and the results showed a small, patchy, high signal that was scattered throughout the left brain hemisphere, right frontal parietal lobe and centrum semiovale. Head and neck CT angiography (CTA) was performed; dissection was found in the ascending aorta, aortic arch, bilateral common carotid artery, proximal part of the internal carotid artery, and initial segment of the left external carotid artery. The laceration was located in the upper part of the ascending aorta. AoD complicated by acute cerebral infarction and epilepsy was considered, and the patient was immediately transferred to the cardiovascular surgery specialist hospital for surgical treatment.

Conclusions: Some aortic dissections have no typical manifestations of chest pain, and the onset is covert. Atypical clinical manifestations of epilepsy secondary to bilateral cerebral hemisphere infarction may appear. AoD with cerebral infarction is a contraindication for intravenous thrombolysis; surgical treatment is the best way to reduce mortality.
\end{abstract}

Keywords: Aortic dissection, Cerebral infarction, Intravenous thrombolysis

\section{Background}

Aortic dissection (AoD) is a disease with a high mortality rate and an incidence of $2.5-3.5 / 100,000$ people per year $[1,2]$. Without early surgical intervention, the mortality of Stanford type A AoD at 3 days after onset is greater than 50\% [3]. The most common initial manifestation of AoD is pain; however, there are certain

\footnotetext{
*Correspondence: 870113579@qq.com

${ }^{\dagger}$ Jie Wang and Li-Rong Wu contributed equally to this work.

Department of Neurology, Chongqing City Hospital of Traditional Chinese Medicine, No. 6, Seventh Branch Road, Panxi, Jiangbei District, Chong qing 400021, China
}

patients with AoD who mainly present with neurological symptoms but do not have pain. These patients are likely to be missed clinically.

The latest guidelines currently treat acute cerebral infarction with $\mathrm{AoD}$ as a contraindication to intravenous thrombolytic therapy [4]. If AoD is not ruled out before intravenous thrombolytic therapy, the consequences will be disastrous and may result in a high mortality rate and poor prognosis [5]. A case of AoD with unusual cerebral infarction occurring at our hospital has now been analysed and reported; it is hoped that this case will serve as a reference for clinical practice.

(c) The Author(s). 2020 Open Access This article is licensed under a Creative Commons Attribution 4.0 International License, which permits use, sharing, adaptation, distribution and reproduction in any medium or format, as long as you give appropriate credit to the original author(s) and the source, provide a link to the Creative Commons licence, and indicate if changes were made. The images or other third party material in this article are included in the article's Creative Commons licence, unless indicated otherwise in a credit line to the material. If material is not included in the article's Creative Commons licence and your intended use is not permitted by statutory regulation or exceeds the permitted use, you will need to obtain permission directly from the copyright holder. To view a copy of this licence, visit http://creativecommons.org/licenses/by/4.0/ The Creative Commons Public Domain Dedication waiver (http://creativecommons.org/publicdomain/zero/1.0/) applies to the data made available in this article, unless otherwise stated in a credit line to the data. 


\section{Case presentation}

The patient was a 54-year-old middle-aged man who experienced acute-onset symptoms. He was admitted to the hospital due to acute onset of weakness in his right limbs accompanied by slurred speech for $2 \mathrm{~h}$. He had a history of hypertension as well as tobacco and alcohol use. The admission examination revealed consciousness, incomplete mixed aphasia, and grade 4 right upper and lower limb muscle strength. No bleeding was seen on the skull CT. Blood tests showed D-dimer $177.60 \mathrm{mg} / \mathrm{l}$ and C-reactive protein $130.8 \mathrm{mg} / \mathrm{l}$, and routine blood tests showed white blood cells $11.43 \times 10^{9} / \mathrm{l}$, red blood cells $3.2 \times 10^{12} / \mathrm{l}$, and haemoglobin $10^{6} \mathrm{~g} / \mathrm{l}$.

Acute cerebral infarction was considered after admission. Recombinant tissue plasminogen activator (rt-PA; $45 \mathrm{mg}$ ) was administered for intravenous thrombolysis. During intravenous thrombolysis, the patient suddenly lost consciousness and exhibited involuntary convulsions in the limbs accompanied by increased salivation. Intravenous thrombolysis was immediately stopped, and 10 $\mathrm{mg}$ diazepam was given by intravenous injection. Emergency CT scan of the skull showed no bleeding after the cessation of convulsions. Emergency skull diffusionweighted imaging (DWI) was performed $1 \mathrm{~h}$ after intravenous thrombolysis, and the results showed a small patchy high signal that was scattered throughout the left brain hemisphere, right frontal parietal lobe and centrum semiovale (Fig. 1). Therefore, acute cerebral infarction was considered. Head and neck CT angiography (CTA) was performed, and dissection was found in the ascending aorta, aortic arch, bilateral common carotid artery, proximal part of the internal carotid artery, and initial segment of the left external carotid artery. The laceration was located in the upper part of the ascending aorta (Fig. 2). Stanford type A AoD complicated by acute cerebral infarction and epilepsy was considered, and the patient was immediately transferred to the cardiovascular surgery specialist hospital for surgical treatment.

\section{Discussion and conclusions}

The pathogenesis of AoD is currently unclear, and the most common causes of AoD are hypertension and atherosclerosis, which account for approximately $80 \%$ of dissection cases. Other factors include trauma, Marfan syndrome, iatrogenic factors, bicuspid aortic valve deformities, familial asymptomatic aortic dissection, intramural haematoma expansion, pregnancy and arteritis [6]. This patient had no obvious history of trauma, but there was a history of untreated hypertension. Therefore, the possible causes of dissection were hypertension and atherosclerosis.

The primary manifestation of AoD is often sudden and persistent chest and back pain that cannot be relieved [7]. Approximately $1 / 3-1 / 2$ of aortic dissections with neurological symptoms have no pain symptoms $[8$, 9]. The possible reason is that these patients often exhibit a disturbance of consciousness, aphasia and/or amnesia, and their ability to communicate is lost [5]. Clinical symptoms are closely related to dissection initiation and pathophysiological development. This patient presented with a bilateral common carotid artery dissection and first showed right hemiplegia. It is speculated that emboli in left common carotid artery dissections are unstable and easily dislodged, while right common carotid artery dissections are asymptomatic. Therefore, signs of damage to the left brain hemisphere were first manifested clinically in our patient. When alteplase was used for intravenous thrombolysis, the bilateral common carotid artery intimal thrombus disintegrated and dislodged, resulting in extensive embolization events in both hemispheres and eventually, secondary epilepsy.

Some auxiliary examinations can also provide some clinical information. For example, $80 \%$ of patients with aortic dissection have a widened mediastinum and abnormal aortic shape when tested with chest X-ray [8]; echocardiography can prompt arterial lumen intimal stripping. Laboratory D-dimer tests can also provide

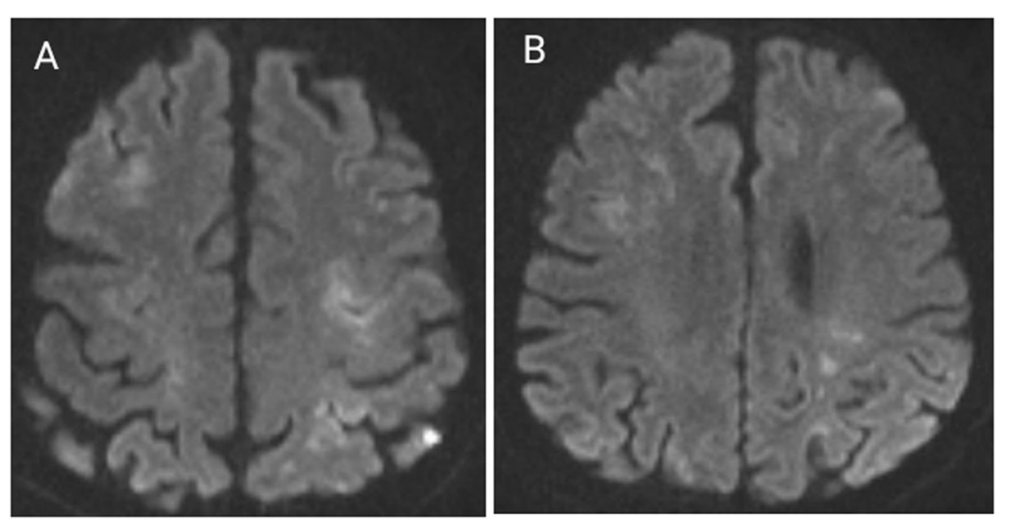

Fig. 1 DWI of the patient showed small patchy high signals scattered throughout the left brain hemisphere and right frontal parietal lobe 

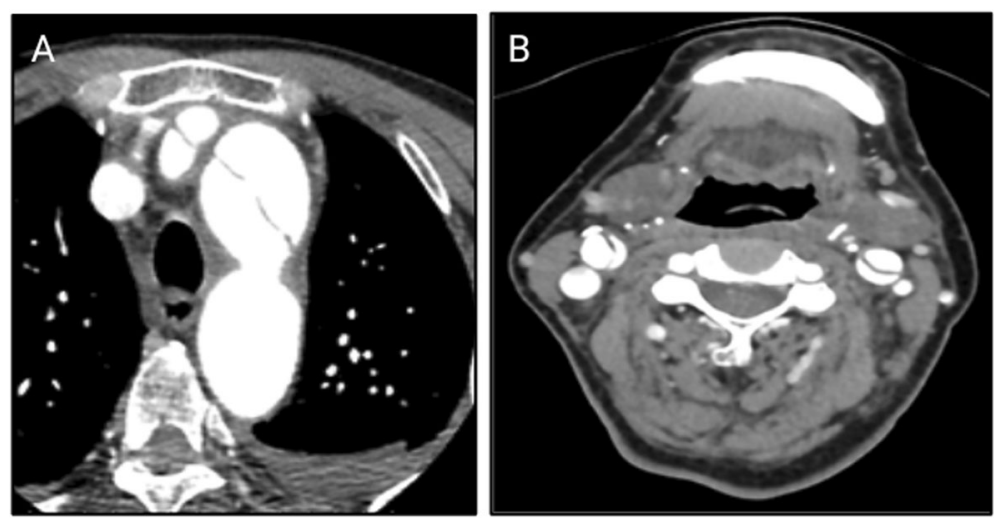

Fig. 2 CT angiography (CTA) images of the patient showed dissection of the ascending aorta, aortic arch and bilateral common carotid arteries

valuable diagnostic information. A study showed that Ddimer levels were significantly higher in patients with ischemic stroke and AoD than in patients without AoD. This trend was evident within $6 \mathrm{~h}$ of the onset of symptoms [10]. Weber et al. found that elevated D-dimer levels are related to the severity of AoD [11].

Currently, the guidelines have recommended intravenous thrombolysis as the highest level of therapy for cerebral infarction within the time window [4]. At this stage, there are many hospitals in China that can perform intravenous thrombolysis, but the level of diagnosis and treatment is uneven. If a patient has AoD, intravenous thrombolysis can have catastrophic consequences, such as new embolic events caused by the disintegration of emboli in the dissection, enlargement of haematomas in the wall of the dissection or around the aorta, pericardial effusion and tamponade due to aortic rupture, and the delay of life-saving surgery [12]. Some AoD patients with neurological defects as the first symptoms have no pain (or the pain cannot be described). Such patients are prone to a missed or delayed diagnosis of AoD. Doctors should also pay attention to any unexplained hypotension, mild dyspnoea, chest discomfort, asymmetry of blood pressure between arms (more than 20 $\mathrm{mmHg}$ difference in systolic blood pressure), loss of consciousness, changes in the electrocardiogram, cardiac murmurs, and cold limbs [13]. If the above symptoms are present, aortic CT angiography and echocardiography should be supplemented to determine whether AoD is present.

Surgery is still the best treatment to reduce the mortality of Stanford type A AoD [14]. Whether neurological complications will affect the prognosis of patients with AoD is still controversial. AoD patients need to maintain a low blood pressure to prevent further tearing or even rupture of the dissection, while low blood pressure will reduce stroke hemisphere perfusion and then enlarge the cerebral infarction [15]. Some researchers believe that concurrent ischaemic stroke is a predictor of poor prognosis in patients with AoD [16, 17]; however, with early diagnosis of AoD and appropriate surgical treatment, concurrent neurological symptoms have been reported to not be associated with increased mortality $[8,18,19]$.

Stanford type A AoD is a high-risk fatal disease. The key to controlling it lies in early detection, early diagnosis, and timely surgical treatment. Approximately $1 \%$ of patients with ultra-acute ischaemic stroke have aortic dissection [20]. Prior to intravenous thrombolysis, it is necessary to increase risk awareness and exclude AoD as much as possible to avoid iatrogenic damage to patients.

\section{Abbreviations}

AoD: Aortic dissection; DWl: Diffusion weighted imaging; CTA: CT angiography; rt-PA: Recombinant tissue plasminogen activator

\section{Acknowledgements}

Not applicable.

\section{Authors' contributions}

JW contributed to the conception, drafting, and reporting of the case. XX acquired the clinical data. LRW contributed to the revision of the manuscript. All authors have read and approved the final manuscript.

\section{Funding}

None.

Availability of data and materials

All data related to this case report are documented within this manuscript.

\section{Ethics approval and consent to participate}

Informed consent was obtained from the patient's wife to publish his case, and approval for this study was provided by the Research Ethics Committee of Chong qing City Hospital of Traditional Chinese Medicine.

\section{Consent for publication}

Written informed consent for publication of this case report was obtained from the patient's wife. A copy of the written consent form is available for review by the Editor of this journal.

Competing interests

The authors declare that they have no competing interests. 
Received: 27 March 2020 Accepted: 18 June 2020

Published online: 23 June 2020

\section{References}

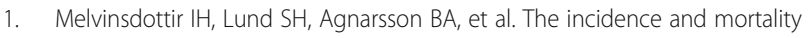
of acute thoracic aortic dissection: results from a whole nation study. Eur J Cardiothorac Surg. 2016;50:1111-7.

2. Clouse WD, Hallett JW Jr, Schaff HV, et al. Acute aortic dissection: population-based incidence compared with degenerative aortic aneurysm rupture. Mayo Clin Proc. 2004;79:176-80.

3. Coady MA, Rizzo JA, Goldstein LJ, et al. Natural history, pathogenesis, and etiology of thoracic aortic aneurysms and dissections. Cardiol Clin. 1999;17: 615-35.

4. Chinese Neurology Association, Chinese Medical Association, China cerebrovascular disease group, Chinese Medical Association. Chinese guidelines for diagnosis and treatment of acute ischemic stroke 2018[J]. Chin J Neurol. 2018;51(9):666-82.

5. Sakamoto Y, Koga M, Ohara T, Ohyama S, Matsubara S, Minatoya K, et al. Frequency and detection of Stanford type a aortic dissection in hyperacute stroke management. Cerebrovasc Dis. 2016;42(1-2):110-6.

6. Pasternak B, Inghammar M, Svanstrm H. Fluoroquinolone use and risk of aortic aneurysm and dissection:nationwidecohortstudy [J]. BMJ. 2018;360(3): 678.

7. Bossone E, Corteville DC, Harris KM, et al. Stroke and outcomes in patients with acute type a aortic dissection [J]. Circulation. 2013;128(11 Suppl 1): S175-9.

8. Gaul C, Dietrich W, Friedrich I, et al. Neurological symptoms in type a aortic dissections. Stroke. 2007;38:292-7.

9. Hagan PG, Nienaber CA, Isselbacher EM, et al. The international registry of acute aortic dissection (IRAD):new insights into an old disease [J]. JAMA. 2000;283(7):897-903.

10. Yoshimuta T, Yokoyama H, Okajima T, et al. Impact of elevated D-dimer on diagnosis of acute aortic dissection with isolated neurological symptoms in ischemic stroke [J]. Circ J. 2015;79(8):1841.

11. Weber T, Högler S, Auer J, Berent R, Lassnig E, Kvas E, et al. D-dimer in acute aortic dissection. Chest. 2003;123:1375-8.

12. Tsivgoulis G, Safouris A, Alexandrov AV. Safety of intravenous thrombolysis for acute ischemic stroke in specific conditions. Expert Opin Drug Saf. 2015; 14:845-64.

13. Koga M, Iguchi $Y$, et al. Acute ischemic stroke as a complication of Stanford type A acute aortic dissection: a review and proposed clinical recommendations for urgent diagnosis. Gen Thor Cardiovasc Surg. 2018.

14. Erbel R, Aboyans V, Boileau C, et al. ESC Committee for Practice Guidelines. 2014 ESC guidelines on the diagnosis and treatment of aortic diseases: document covering acute and chronic aortic diseases of the thoracic and abdominal aorta of the adult. The task force for the diagnosis and treatment of aortic diseases of the European Society of Cardiology (ESC)[J]. Eur Heart J. 2014;35(41):2873-926.

15. Guglielmi V, Groeneveld NS, Posthuma L, et al. Aortic dissection masquerading as a code stroke: a single-Centre cohort study [J]. Eur Stroke J. 2019;2396987319883713.

16. Pansini S, Gagliardotto PV, Pompei E, Parisi F, Bardi G, Castenetto E, et al. Early and late risk factors in surgical treatment of acute type a aortic dissection. Ann Thorac Surg. 1998;66(3):779-84.

17. Ehrlich MP, Ergin MA, McCullough JN, Lansman SL, Galla JD, Bodian CA, et al. Results of immediate surgical treatment of all acute type a dissections. Circulation. 2000;102(19 Suppl 3):III248-52.

18. Trimarchi S, Nienaber CA, Rampoldi V, Myrmel T, Suzuki T, Mehta RH, et al. Contemporary results of surgery in acute type a aortic dissection: the international registry of acute aortic dissection experience. J Thorac Cardiovasc Surg. 2005;129(1):112-22.

19. Ueyama K, Otaki K, Koyama M, Kamiyama H. Urgent simultaneous revascularization of the carotid artery and ascending aortic replacement for type a acute aortic dissection with cerebral malperfusion. Gen Thorac Cardiovasc Surg. 2007;55(7):284-6.

20. Iguchi Y, Kimura K, Sakai K, et al. Hyper-acute stroke patients associated with aortic dissection [J]. Intern Med. 2010;49(6):543-7.

\section{Publisher's Note}

Springer Nature remains neutral with regard to jurisdictional claims in published maps and institutional affiliations.

Ready to submit your research? Choose BMC and benefit from:

- fast, convenient online submission

- thorough peer review by experienced researchers in your field

- rapid publication on acceptance

- support for research data, including large and complex data types

- gold Open Access which fosters wider collaboration and increased citations

- maximum visibility for your research: over $100 \mathrm{M}$ website views per year

At BMC, research is always in progress.

Learn more biomedcentral.com/submissions 